\title{
ASSESSMENT OF GROUND SHAKING IN ILAN COUNTY, TAIWAN
}

Hui-Mi Hsu

Department of Civil Engineering and Graduate Institute of Architecture and Sustainable Planning, National Ilan University, Ilan, Taiwan, R.O.C.

Sao-Jeng Chao

Department of Civil Engineering, National Ilan University, Ilan, Taiwan, R.O.C., Chao@niu.edu.tw

Howard Hwang

College of Engineering, National Ilan University, Ilan, Taiwan, R.O.C.

Follow this and additional works at: https://jmstt.ntou.edu.tw/journal

Part of the Civil and Environmental Engineering Commons

\section{Recommended Citation}

Hsu, Hui-Mi; Chao, Sao-Jeng; and Hwang, Howard (2008) "ASSESSMENT OF GROUND SHAKING IN ILAN COUNTY, TAIWAN," Journal of Marine Science and Technology. Vol. 16: Iss. 4, Article 10.

DOI: 10.51400/2709-6998.2018

Available at: https://jmstt.ntou.edu.tw/journal/vol16/iss4/10

This Research Article is brought to you for free and open access by Journal of Marine Science and Technology. It has been accepted for inclusion in Journal of Marine Science and Technology by an authorized editor of Journal of Marine Science and Technology. 


\section{ASSESSMENT OF GROUND SHAKING IN ILAN COUNTY, TAIWAN}

\section{Acknowledgements}

The research project is supported by the National Science and Technology Center for Disaster Reduction under the grant number NCDR-95-A5000-CO-N001. The authors wish to thank Dr. Kou Cheng Chen of the Academia Sinica and Mr. Shih Hao Hsu of the National Ilan University for their assistance in carrying out the project. 


\title{
ASSESSMENT OF GROUND SHAKING IN ILAN COUNTY, TAIWAN
}

\author{
Hui-Mi Hsu*, Sao-Jeng Chao**, and Howard Hwang***
}

Key words: earthquakes, faults, ground shaking, site condition.

\begin{abstract}
This paper presents an estimation of ground shaking intensity in the Ilan area caused by two scenario earthquakes. On the basis of seismic activity in the study area, the seismic zones, including Okinawa trough seismic zone section A and Suao-Hualien offshore seismic zone are established. The earthquakes occurring in these two zones are considered as the scenario earthquakes. The hundreds of boring logs are also collected and classified into three site classes as specified in the Taiwan Seismic Building Code. The intensity of ground shaking in the Ilan area caused by a scenario earthquake is then estimated by using an appropriate attenuation relation and a site modification factor. When the scenario earthquake occurs in the Okinawa trough seismic zone section A, the intensity of ground shaking is more severe in Lotung Town and Ilan City. On the other hand, when the scenario earthquake occurs in the Suao-Hualien offshore seismic zone, the intensity of ground shaking is more severe in Suao Town. The results of this study may be used to simulate seismic disaster scenarios and then to implement a strategy for seismic disaster reduction.
\end{abstract}

\section{INTRODUCTION}

A large earthquake will induce severe ground shaking in a wide area. As a consequence, it may result in loss of human lives and severe damage to properties. Thus, it is important to have an accurate estimate of the intensity of ground shaking in a wide area caused by an earthquake. In this study, the intensity of ground shaking in the Ilan area caused by two scenario earthquakes is estimated. First, five seismic zones in the Ilan area are established based on the seismic activity in the study area. Two of them, which may have a significant impact on the built environment in the study area, are selected as the scenario earthquakes. Several hundreds of boring logs are collected and

Paper submitted 01/15/07; accepted 12/24/07. Author for correspondence: Sao-Jeng Chao (e-mail:chao@niu.edu.tw).

* Department of Civil Engineering and Graduate Institute of Architecture and Sustainable Planning, National Ilan University, Ilan, Taiwan, R.O.C.

**Department of Civil Engineering, National Ilan University, Ilan, Taiwan, R.O.C.

***College of Engineering, National Ilan University, Ilan, Taiwan, R.O.C. classified into three site classes as specified in the Taiwan Seismic Building Code. The intensity of ground shaking in the Ilan area caused by a scenario earthquake is estimated by using an appropriate attenuation relation and a site modification factor. The results of this study may be used to simulate seismic disaster scenarios and to implement a strategy for seismic disaster reduction in the study area.

\section{SEISMICITY IN THE ILAN AREA}

Taiwan is situated in the colliding area of the Philippine Sea plate and Eurasian continental plate. The Philippine Sea plate moves in the northwestern direction with a speed of about 70 to $80 \mathrm{~mm}$ per year and collides with the eastern margin of the Eurasian continental plate, resulting in the Ryukyu subduction zone in the northeastern offshore of Taiwan [7]. The degree of collision is most intense along the eastern coast and offshore. As a result, large earthquakes may often occur in this region, including the Ilan area.

In this study, the seismic activity around the Ilan area is investigated based on the seismic data in the time period of 1900 to 2005. Fig. 1 shows the distribution of epicenters of earthquakes in the study area. A big star indicates the epicenter of an earthquake with a magnitude larger than 7.0; a medium star indicates the epicenter of an earthquake with a magnitude of 6.0 - 6.9; a small star indicates the epicenter of an earthquake with a magnitude of 5.0 - 5.9; a round dot indicates the epicenter of an earthquake with a magnitude of 2.0 - 4.9. From the distribution of epicenters, seismic source zones can be identified.

As shown in Fig. 1, a cluster of epicenters extending from Lanyang Plain to Okinawa trough is observed and it is identified as the Okinawa trough seismic zone. In this study, a seismic zone is considered as a line fault. Because some software assumes a line fault as a straight line, the Okinawa trough seismic zone are divided into two sections, Okinawa trough seismic zone section A from Lanyang Plain to Turtle Mountain and Okinawa trough seismic zone section B from Turtle Mountain to offshore. Since the Okinawa trough is in tension, the Okinawa trough seismic zone is considered as a normal fault [2].

According to Wells and Coppersmith [3], the moment magnitude $\mathrm{M}_{\mathrm{W}}$ of a normal fault can be calculated from its fault length as follows:

$$
\mathrm{M}_{\mathrm{W}}=4.86+1.32 \log (\mathrm{L})
$$

where $\mathrm{M}_{\mathrm{W}}$ is the moment magnitude and $\mathrm{L}$ is the fault length 
Table 1. Source parameters of five seismic zones in the Ilan area.

\begin{tabular}{|c|c|c|c|c|c|c|c|c|}
\hline \multirow[b]{2}{*}{ Seismic sources } & \multirow{2}{*}{$\begin{array}{l}\text { Fault } \\
\text { types }\end{array}$} & \multirow{2}{*}{$\begin{array}{c}\text { Fault } \\
\text { length } \\
(\mathrm{km})\end{array}$} & \multirow{2}{*}{$\begin{array}{c}\text { Fault } \\
\text { azimuth } \\
\left({ }^{\circ}\right)\end{array}$} & \multicolumn{2}{|c|}{ Epicenter } & \multirow[b]{2}{*}{$\mathrm{M}_{\mathrm{W}}$} & \multirow[b]{2}{*}{$\mathrm{M}_{\mathrm{L}}$} & \multirow{2}{*}{$\begin{array}{c}\text { Focus } \\
\text { depth } \\
(\mathrm{km})\end{array}$} \\
\hline & & & & Longitude $\left(^{\circ}\right)$ & Latitude $\left(^{\circ}\right)$ & & & \\
\hline $\begin{array}{l}\text { Okinawa trough seis- } \\
\text { mic zone section A }\end{array}$ & $\begin{array}{c}\text { Normal } \\
\text { fault }\end{array}$ & 35 & 60 & 121.869 & 24.742 & 6.9 & 6.7 & 10 \\
\hline $\begin{array}{l}\text { Okinawa trough seis- } \\
\text { mic zone section B }\end{array}$ & $\begin{array}{c}\text { Normal } \\
\text { fault }\end{array}$ & 50 & 90 & 122.266 & 24.820 & 7.1 & 6.8 & 10 \\
\hline Suao seismic zone & $\begin{array}{l}\text { Strike-slip } \\
\text { fault }\end{array}$ & 10 & 60 & 121.799 & 24.649 & 6.3 & 6.2 & 7 \\
\hline $\begin{array}{l}\text { Suao-Hualien near- } \\
\text { shore seismic zone }\end{array}$ & $\begin{array}{c}\text { Thrust } \\
\text { fault }\end{array}$ & 100 & 25 & 121.652 & 24.015 & 7.4 & 7.0 & 10 \\
\hline $\begin{array}{l}\text { Suao-Hualien offshore } \\
\text { seismic zone }\end{array}$ & $\begin{array}{l}\text { Thrust } \\
\text { fault }\end{array}$ & 55 & 125 & 122.03 & 24.367 & 7.1 & 6.8 & 10 \\
\hline
\end{tabular}

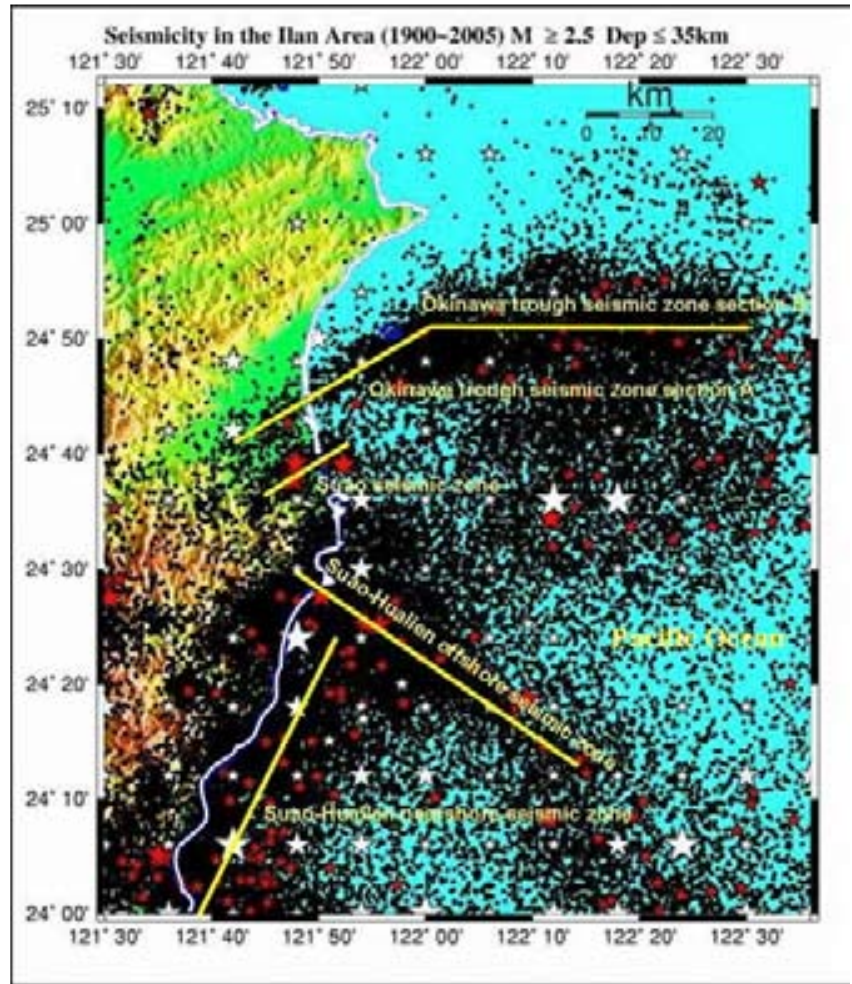

Fig. 1. Seismic source zones in the Ilan area.

(km). Using Equation (1), the moment magnitude of the Okinawa trough seismic zone section $\mathrm{A}$ is determined as 6.9 based on a fault length of $35 \mathrm{~km}$.

According to Wu et al. [4], the Richter magnitude $\mathrm{M}_{\mathrm{L}}$ and the moment magnitude $\mathrm{M}_{\mathrm{W}}$ is related as follows:

$$
\mathrm{M}_{\mathrm{L}}=4.533 \ln \left(\mathrm{M}_{\mathrm{W}}\right)-2.091
$$

Using Equation (2), the Richter magnitude of the Okinawa trough seismic zone section A is determined as 6.7. On January 16,1986 , an earthquake occurred in the Okinawa trough seismic zone. The Richter magnitude of the earthquake is 6.1 and the focal depth is $10.22 \mathrm{~km}$. On the basis of this earthquake, the focal depth of earthquakes occurring in the Okinawa trough seismic zone section A is set as $10 \mathrm{~km}$. From Fig. 1, the fault azimuth of the Okinawa trough seismic zone section $\mathrm{A}$ is

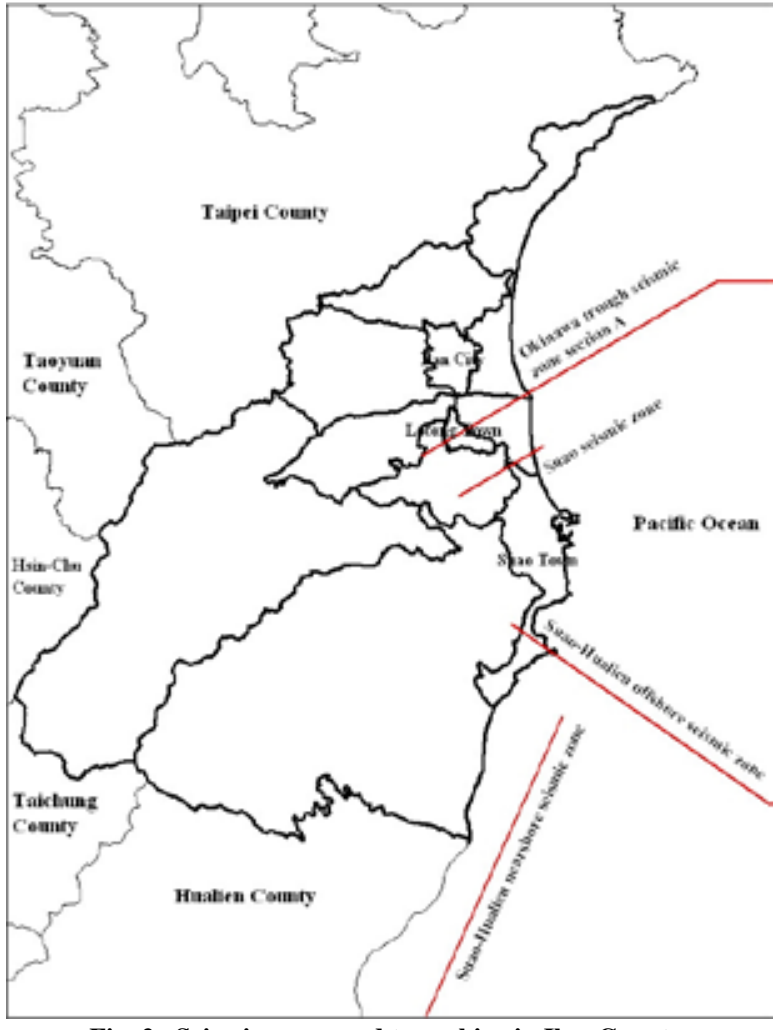

Fig. 2. Seismic zones and townships in Ilan County.

measured as $60^{\circ}$.

Following this procedure, five seismic source zones are identified, which include Okinawa trough seismic zone section A, Okinawa trough seismic zone section B, Suao seismic zone, Suao-Hualien nearshore seismic zone and Suao-Hualien offshore seismic zone as shown in Fig. 1. The fault parameters, such as fault types, fault length, fault azimuth, moment magnitude, and Richter magnitude, are determined and summarized in Table 1 .

Fig. 2 shows the relation of seismic zones and townships in Ilan County. As shown in Fig. 2, the Okinawa trough seismic zone section A extends into the Lanyang Plain passing through Lotung Town, and the Suao-Hualien offshore seismic zone also extends into Suao Town. Thus, a large earthquake occurring in 


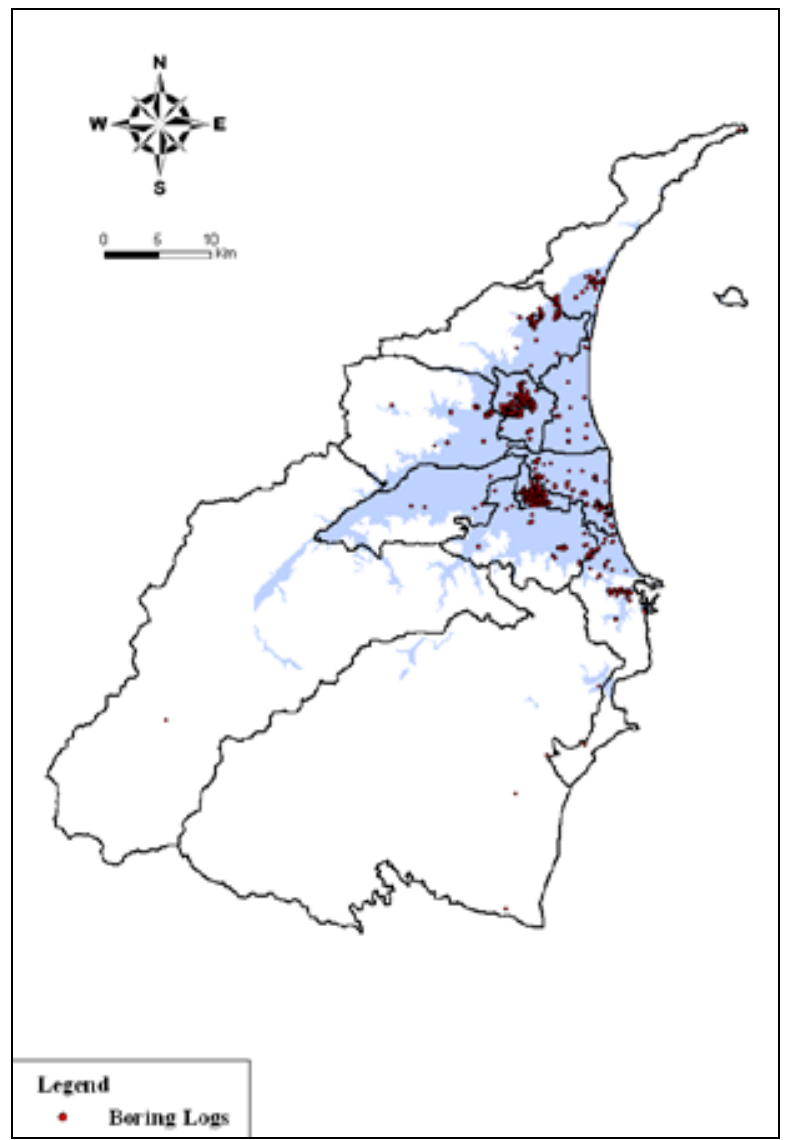

Fig. 3. Distribution of boring logs in Ilan County.

these two seismic zones may have significant effects on the built environment in the study area. On the other hand, the Suao seismic zone is also located within the Ilan County, but the magnitude of earthquakes occurring in this seismic zone is limited to 6.2, which is much smaller the magnitudes of other seismic zones. Thus, the effect on built environment caused by an earthquake in the Suao seismic zone is expected to be less significant. Furthermore, the Okinawa trough seismic zone section B and the Suao-Hualien nearshore seismic zone are situated in the open sea area away from the Ilan County. Thus, the effects of earthquakes occurring in these two seismic zones may be limited. On the basis of these discussions, the earthquakes occurring in the Okinawa trough seismic zone section A and the Suao-Hualien offshore seismic zone are considered as the scenario earthquakes for the estimation of the intensity of ground shaking in the study area.

\section{SITE CONDITIONS IN THE ILAN AREA}

The Ilan County is located in the northeast of Taiwan. It is surrounded by the Snow mountain range in the northwestern side and the Central mountain range in the southeastern side and it faces the Pacific Ocean in the east. The Lanyang Plain, which is surrounded by mountain ranges and ocean, is a sedimentary deposit from several rivers. In this study, several hundreds of boring logs are collected and the locations of these boring logs

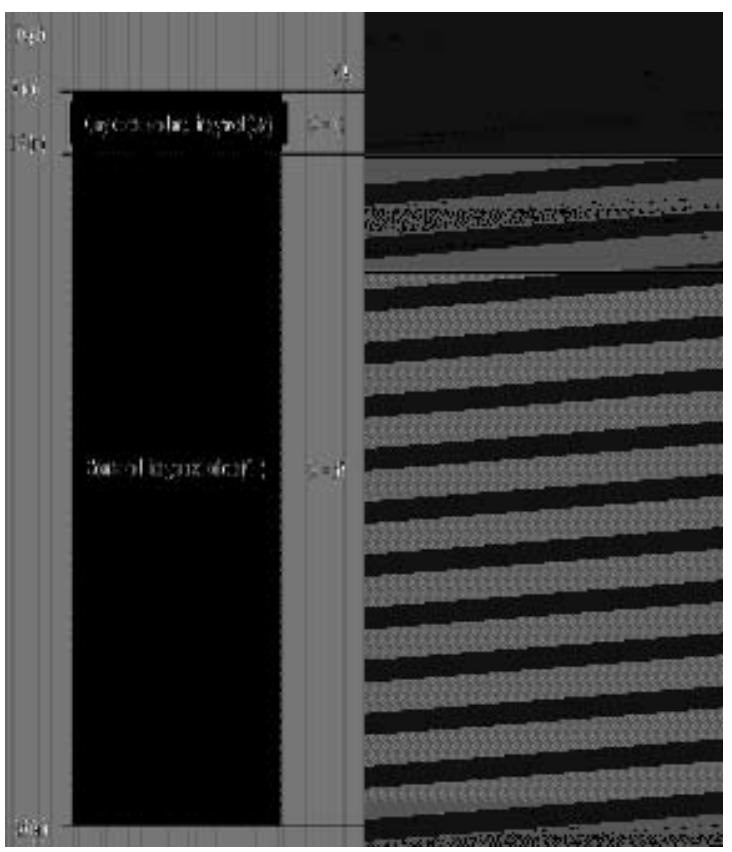

Fig. 4. A soil profile of first site class in Ilan County.

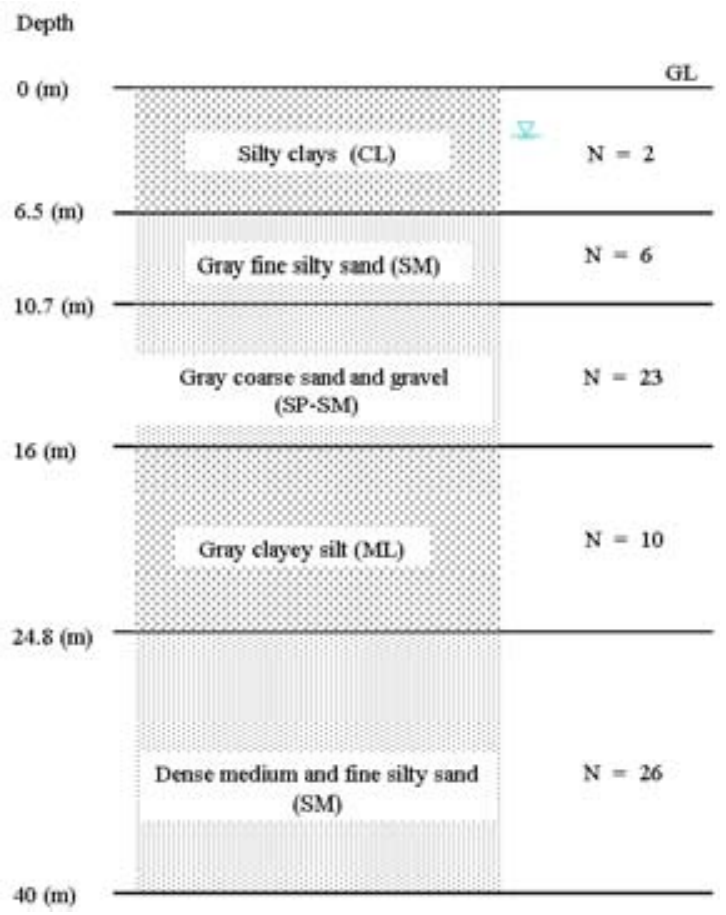

Fig. 5. A soil profile of second site class in Ilan County.

are shown in Fig. 3. In addition, these boring logs are classified into three site classes according to the criteria specified in the Taiwan Seismic Building Code. The first site class is rock site or firm soil site, the second site class is regular soil site and the third site class is soft soil site. For illustration, a profile for each site class is shown in Figs. 4 to 6, respectively for first site class, second site class, and third site class. The results of site classification from this study are consistent with that used in the TELES software [5] compiled by the National Center for Earthquake Engineering Research (NCREE) as shown in Fig. 7. 


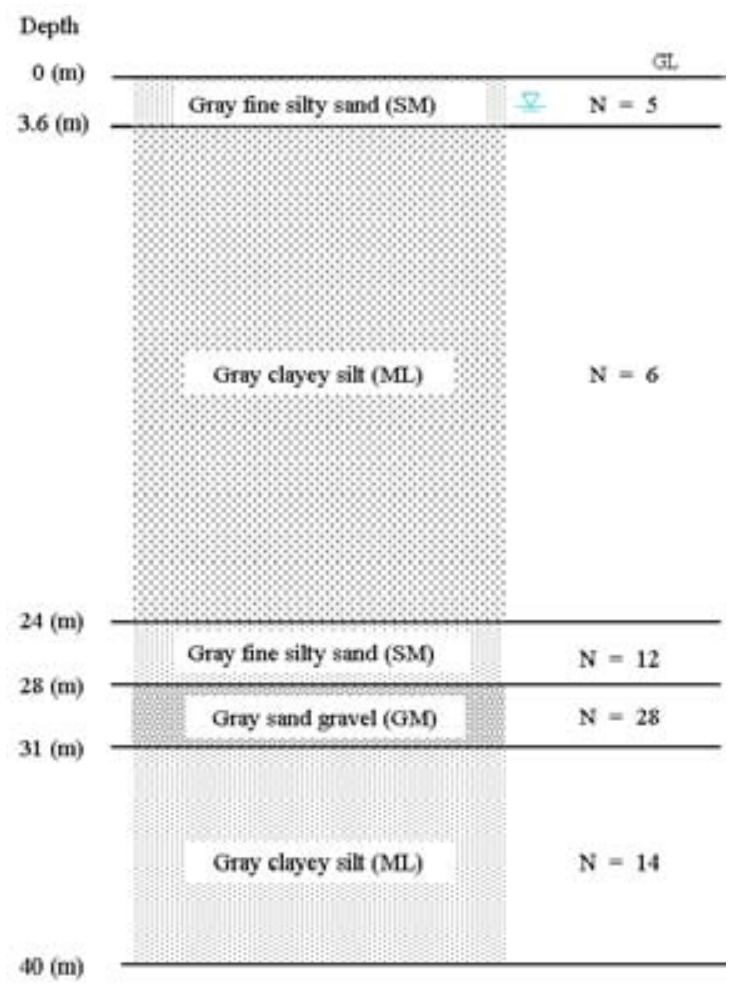

Fig. 6. A soil profile of third site class in Ilan County.

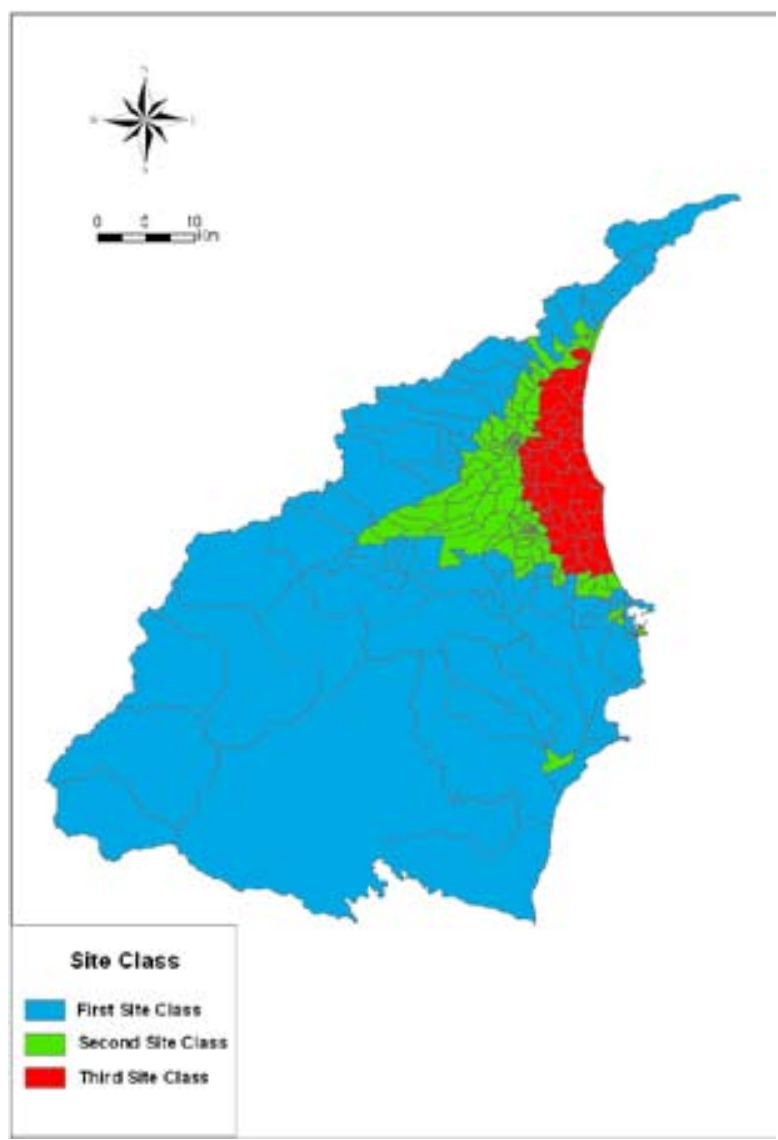

Fig. 7. Distribution of site classes in Ilan County.

\section{ESTIMATION OF GROUND SHAKING INTENSITY}

The intensity of ground shaking caused by an earthquake is affected by many factors, such as the characteristics of seismic source, the attenuation of seismic waves from the source to a site, and local soil condition at the site. In this study, the intensity of ground shaking is estimated based on an attenuation relation and a site modification factor. Chien [1] used seismic data with various site classes from past earthquakes in Taiwan to establish a ground motion attenuation relation. For an average site condition, the attenuation relation established by Chien is as follows:

$$
A=A_{0} e^{a M_{L}}\left[R+b e^{c M_{L}}\right]^{-d}
$$

where $\mathrm{A}$ is the peak ground acceleration in an average site condition ( in a unit of $\mathrm{g}$ ), $\mathrm{M}_{\mathrm{L}}$ is the Richter magnitude, $\mathrm{R}$ is the shortest source distance, $\mathrm{A}_{0}, \mathrm{a}, \mathrm{b}, \mathrm{c}$ and $\mathrm{d}$ are the regression coefficients. For the peak ground acceleration, the coefficient $\mathrm{A}_{0}$ is 0.0036944 , a is $1.7537666, \mathrm{~b}$ is 0.1221955 , $\mathrm{c}$ is 0.7831508 , and $\mathrm{d}$ is 2.0564446 .

For a site with a different site classification, a site modification factor is needed to adjust the A value. The site modification factors recommended by Yeh et al. [6] as listed in Table 2 are used in this study. As recommended by Yeh et al, the relation of $\mathrm{A}$ and PGA is linear when $\mathrm{A}$ is between $0.1 \mathrm{~g}$ and $0.8 \mathrm{~g}$. Therefore, a linear interpolation may be used to obtain the peak ground acceleration (PGA) when the $\mathrm{A}$ value is different with those listed in Table 2. It can be seen from the table, when A is equal to $0.1 \mathrm{~g}$, which may be caused by a moderate or a minor earthquake, the PGA values are $0.0973,0.1025$ and 0.1419 , for the first site class, the second site class, and the third site class, respectively; thus the PGA value is amplified 1.053 times due to the effect of the second site class and the PGA value is amplified 1.458 times due to the effect of the third site class. On the other hand, when A is equal to $0.4 \mathrm{~g}$, which may be caused by an severe earthquake, the PGA values are $0.3982,0.4017$, and 0.4279 , for the first site class, the second site class, and the third site class, respectively; thus the PGA value is amplified only 1.009 times due to the effect of the second site class and the PGA value is amplified 1.075 times due to the effect of the third site class. Thus, a soft site (third site class) has a large site amplification factor when a moderate/minor earthquake occurs, but the site amplification factor becomes smaller, when a severe earthquake occurs. This is due to the nonlinear site effect.

In this study, the Shen Lung Li in Ilan City is used as an example to demonstrate the procedure for calculating the intensity of ground shaking caused by a Richter magnitude 6.7 scenario earthquake occurring in the Okinawa trough seismic zone section A. Using a GIS software as a tool, the epicenter distance is measured as $7.5 \mathrm{~km}$, so the shortest source distance $\mathrm{R}$ is $12.5 \mathrm{~km}$. Using Equation (3), the peak ground acceleration A with an average site condition at the Shen Lung Li is estimated as follows:

$$
\begin{aligned}
\mathrm{A} & =0.0036944 \mathrm{e}^{1.7537666(6.7)}\left[12.5+0.1221955 \mathrm{e}^{0.7831508(6.7)}\right]^{-2.0564446} \\
& =0.30 \mathrm{~g}
\end{aligned}
$$




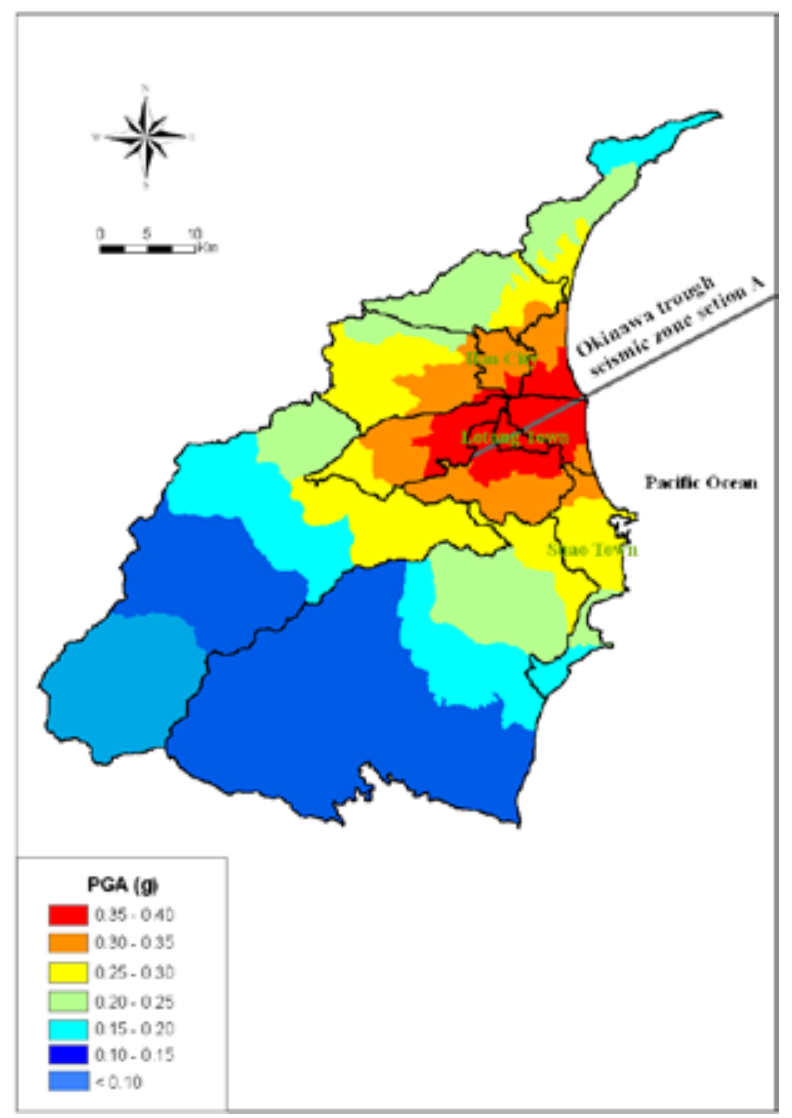

Fig. 8. Distribution of PGA in Ilan County caused by an $M_{L} 6.7$ earthquake occurring in the Okinawa trough seismic zone section $\mathrm{A}$.

The actual site condition in the Shen Lung Li is classified as the second site class. Thus, using site modification factors of the second site class in Table 2, the peak ground acceleration at the Shen Lung Li is obtained as follows:

$\mathrm{PGA}=0.2022+(0.4017-0.2022) / 0.2 \times(0.30-0.2)=0.302 \mathrm{~g}$

Following this procedure, the PGA values for the Ilan County caused by the two scenario earthquakes are determined. The result from the scenario earthquake occurring in the Okinawa trough seismic zone section A is shown in Fig. 8. The intensity of ground shaking is more severe in Lotung Town and Ilan City. Similarly, the result from the scenario earthquake occurring in the Suao-Hualien offshore seismic zone is shown in Fig. 9. The intensity of ground shaking is more severe in Suao Town.

\section{CONCLUSION}

In this study, two scenario earthquakes are considered; one occurs in the Okinawa trough seismic zone section A and the other occurs in the Suao-Hualien offshore seismic zone. The intensity of ground shaking at a site is estimated based on an appropriate attenuation relation and a site modification factor. The results from these two scenario earthquakes are shown in Figs. 8 and 9. When the scenario earthquake occurs in the Okinawa trough seismic zone section A, the intensity of ground shaking is more severe in Lotung Town and Ilan City. On the

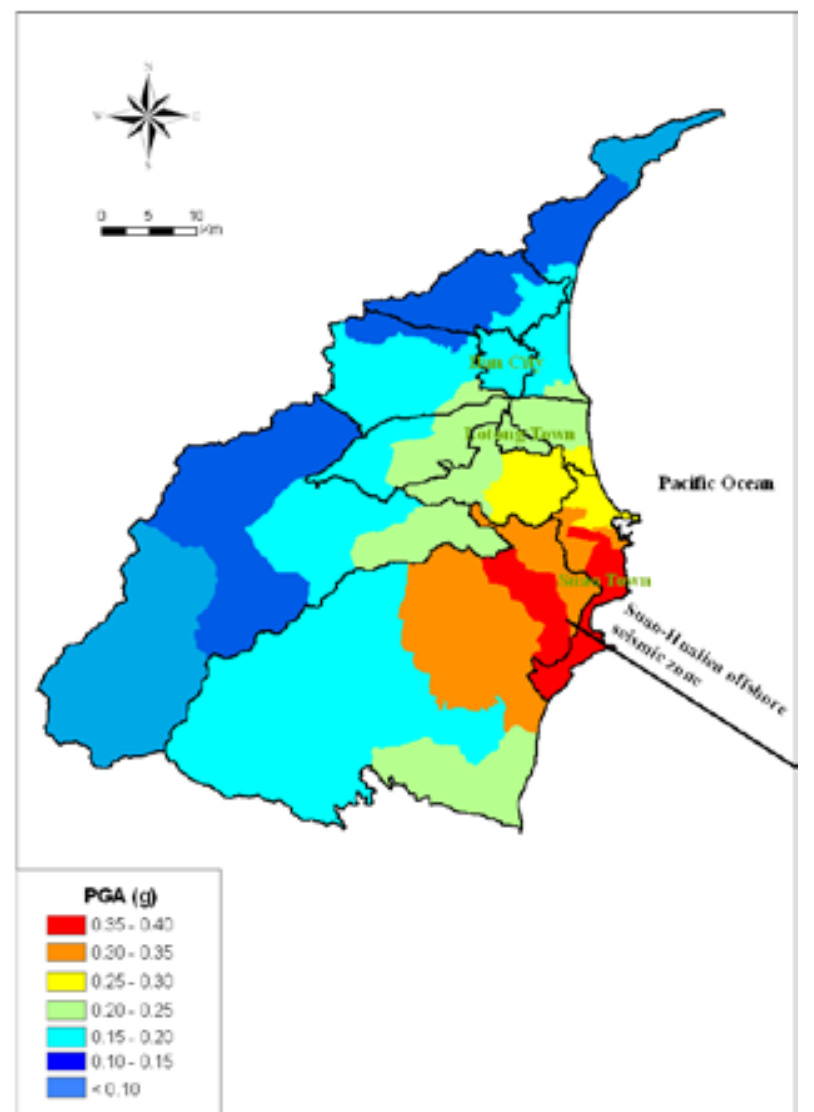

Fig. 9. Distribution of PGA in Ilan County caused by an $M_{L} 6.8$ earthquake occurring in the Suao-Hualien offshore seismic zone.

other hand, when the scenario earthquake occurs in the Suao-Hualien offshore seismic zone, the intensity of ground shaking is more severe in Suao Town. The results of this study may be used to perform simulation of seismic disaster scenarios, including evaluation of damage to buildings and estimation of casualties and economic losses. The results may then be used to implement a strategy for seismic disaster reduction in the study area.

\section{ACKNOWLEDGMENTS}

The research project is supported by the National Science and Technology Center for Disaster Reduction under the grant number NCDR-95-A5000-CO-N001. The authors wish to thank Dr. Kou Cheng Chen of the Academia Sinica and Mr. Shih Hao Hsu of the National Ilan University for their assistance in carrying out the project.

\section{REFERENCES}

1. Chien, W. U., Seismic Hazard Analysis with the Consideration of Characteristic Earthquake and Site Effects, Technical Report NCREE-01-036, National Center for Research on Earthquake Engineering, Taipei, Taiwan (2001) (in Chinese).

2. Wang, C. M., Yang, L., Chou, C. P., Chang, Y. C. and Lee, C. S., "Westward extension of the okinawa trough at its western end in the northern Taiwan area: bathymetric and seismological evidence," Terrestrial, Atmospheric and Oceanic Sciences (TAO), Vol. 11, pp. 459-480 (2000). 
3. Wells, D. L. and Coppersmith, K. J., "New empirical relationships among magnitude, rupture length, rupture width, rupture area, and surface displacement," Bulletin of the Seismological Society of America, Vol. 84, pp. 974-1002 (1994).

4. Wu, Y. M., Chang, J. S., Shin, T. C. and Chien W. U., "Study of strong motion limit value in fast-respond system," Proceedings of the 8th Taiwan Earthquake Science Conferences, Taipei, Taiwan (2000) (in Chinese).

5. Yeh, C. H., Taiwan Earthquake Loss Estimation System - TELES,
Technical Report NCREE-03-002, National Center for Research on Earthquake Engineering, Taipei, Taiwan (2003) (in Chinese).

6. Yeh, C. H., Chien, W. U., and Chung, L. L., "Development of early estimation system for seismic disasters in Taiwan," Journal of the Chinese Institute of Civil and Hydraulic Engineering, Vol. 16, No. 4, pp. 609-620 (2004) (in Chinese).

7. Yu, S. B., Chen, H. Y. and Kuo, L. C., "Velocity field of GPS stations in the Taiwan area," Tectonophysics, Vol. 274, pp. 41-59 (1997). 
